Proc. Indian Acad. Sci. (Chem. Sci.), Vol. 107, No. 5, October 1995, pp. 567-572.

(C) Printed in India.

\title{
Oxidation of substituted benzylic hydrocarbons and naphthalenes by peroxydisulphate in the presence of metal ions
}

\author{
P THIRUMALAI PERUMAL ${ }^{\#}$ and M VIVEKANANDA BHATT* \\ Department of Organic Chemistry, Indian Institute of Science, Bangalore 560012, \\ India \\ "Present address: Organic Division, Central Leather Research Institute, Adyar, \\ Madras 600020, India
}

MS received 10 April 1995; revised 10 August 1995

\begin{abstract}
Oxidations of various substituted benzylic hydrocarbons with peroxydisulphate in the presence of metal ion catalysts like iron, nickel, copper, cobalt, silver and cerium were examined. Among the metal ions copper (II) catalysed reaction gives products in excellent yield, whereas oxidation of naphthalene and substituted naphthalenes gives low to moderate yield of the products with peroxydisulphate - copper (II).
\end{abstract}

Keywords. Metal ion catalysed oxidation; benzylic hydrocarbons; substituted naphthalenes and potassium peroxydisulphate.

\section{Introduction}

Oxidation of phenols by potassium peroxydisulphate under the alkaline condition (Baker and Brown 1948) constitutes the well-known Elbs oxidation reaction of conversion of phenols to dihydroxy compounds. Although the reaction was discovered in 1893 (Elbs 1893), it was only after 1960 that serious mechanistic work has been carried out (Behrman 1963; Ogata and Akada 1970). Evidence has been provided for the formation of sulphate ester of dihydroxy phenols (Baker and Brown 1948; Bacon et al 1954; Behrman 1963; Ogata and Akada 1970) through nucleophilic attack of phenoxide ions on the peroxy $\mathrm{O}-\mathrm{O}$ bond.

Under neutral or acidic conditions, oxidation of aromatic substrates by peroxydisulphate in the presence of metal ion as a catalyst proceeds through an electron transfer mechanism. Sulphate radical anion or metal ions would involve in the electron transfer process (Ledwith and Russel 1974; Walling and Camaioni 1975; Asworth et al 1978; Nyberg and Wistrand 1978; Giordano and Belli 1979).

Oxidation of naphthalene by peroxydisulphate in the presence of copper (II) acetate gave acetoxynaphthalene (Giordano and Belli 1979). Oxidation of naphthalene with silver (II) bis(2,2'-bipyridine) peroxydisulphate in acetic acid medium provided 1-acetoxynaphthalene (Nyberg and Wistrand 1978). Oxidation of aromatic substrate by peroxydisulphate in the presence of iron (II) or copper (II) provided phenolic products in moderate yields (Walling and Camaioni 1975). In the case of benzylic hydrocarbon, a mixture of benzylic alcohols and phenolic products was obtained.

*For correspondence 
Oxidation of aromatic substrates with peroxydisulphate in the presence of copper (II) chloride gave mostly the ring substituted products (Ledwith and Russel 1974). But there are not many reports on comparative studies of the oxidation of aromatic substrates with peroxydisulphate with different metal ions. Recently we have reported the oxidation of halophenols with peroxydisulphate in the presence of metal ions like copper, silver and iron (Perumal and Bhatt 1989). We have also reported previously the oxidations of various benzylic and electron-rich benzylic hydrocarbons with peroxydisulphate in presence of copper (II) sulphate in aqueous acetonitrile medium (Bhatt and Perumal 1981; Perumal and Bhatt 1989). In this paper, we are reporting the oxidation of some substituted benzylic hydrocarbons with peroxydisulphate in the presence of metal ions like copper, iron, nickel, cobalt, cerium and silver in aqueous acetonitrile or acetic acid. We are also reporting the oxidation of substituted naphthalenes with potassium peroxydisulphate in the presence of copper (II) sulphate in aqueous acetic acid to provide naphthoquinones in low to moderate yields.

\section{Results and discussion}

Oxidation of benzylic hydrocarbons with peroxydisulphate in presence of metal ions like copper, iron, cobalt and nickel in aqueous acetic acid medium gives benzylacetate, carbonyl compounds and substituted benzoic acids depending on the substrates (scheme 1). The results are summarised in table 1. Among these catalysts, copper catalysed oxidation gives better yields of the products ( $84-90 \%$ conversion). Oxidation of electron-rich benzylic hydrocarbons with peroxydisulphate in the presence of metal ions like copper, iron, silver and cerium in aqueous acetonitrile medium provides carbonyl compounds and substituted benzoic acids (scheme 1); the results are given in table 2. Here also the copper-catalysed reaction provides better yields than other metal ions. Persulphate-copper (II) system uniformly gives better yields in the oxidation of halophenols to haloquinones (Perumal and Bhatt 1989) and of benzylic hydrocarbons to carbonyl compounds. Our results do not enable us to suggest a unique mechanism. More data are necessary before a mechanism can be advanced. However, based on our results we have proposed the following mechanism for this type of reaction (scheme 1).

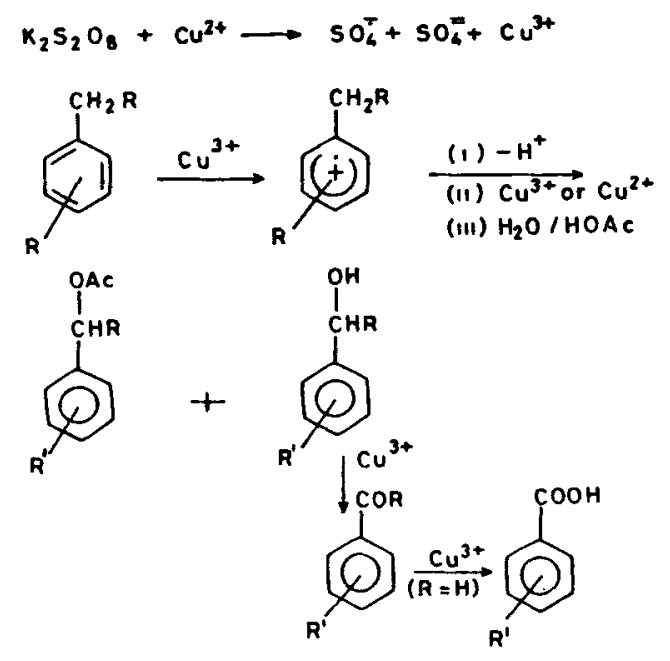

Scheme 1 . 
Table 1. Oxidation of benzylic hydrocarbons with peroxydisulphate ${ }^{a}$ in presence of copper (II) ${ }^{\mathrm{b}}$, cobalt (II) $)^{\mathrm{b}}$, nickel (II) ${ }^{\mathrm{b}}$ and iron (III) ${ }^{\mathrm{b}}$ in aqueous acetic acid.

\begin{tabular}{lllrrr}
\hline \multirow{2}{*}{ Substrate } & \multicolumn{1}{c}{ Products $^{\mathrm{c}}$} & \multicolumn{4}{c}{$\%$ of yields using } \\
\cline { 3 - 6 } Ethylbenzene & Acetophenone & $\mathrm{Cu}^{2+}$ & $\mathrm{Co}^{2+}$ & $\mathrm{Ni}^{2+}$ & $\mathrm{Fe}^{3+}$ \\
& 1-Phenyl-1-ethyl acetate & $13 \cdot 5$ & 6 & 12 & 17 \\
$p$-Xylene & $p$-Tolualdehyde & 47 & 27 & 4 & 1 \\
& $p$-Methylbenzyl acetate & $12 \cdot 5$ & 4 & 6 & 15 \\
\multirow{5}{*}{$o-$-Xylene } & $p$-Toluic acid & 26 & 10 & 4 & 3 \\
& $o$-Tolualdehyde & 28 & 23 & 6 & 1 \\
& $o$-Methylbenzyl acetate & 35 & 5 & 8 & 17 \\
& $o$-Toluic acid & 20 & 4 & 4 & 3 \\
\hline
\end{tabular}

${ }^{a} \mathrm{Mol}$ ratio of peroxydisulphate was 2 ; ${ }^{b} \mathrm{Mol}$ ratio of catalysts was 0.2 (i) $\mathrm{Cu}$ : copper sulphate; (ii) Ni: Nickel sulphate; (iii) Co: cobalt sulphate; (iv) Fe: ferric ammonium sulphate; ${ }^{\mathrm{C}}$ Products were isolated by either distillation or preparative TLC using 1:1 chloroform/hexane $\left(40-60^{\circ} \mathrm{C}\right)$ and identified by NMR and IR spectra

Table 2. Oxidation of electron-rich benzylic hydrocarbons with peroxydisulphate ${ }^{a}$ in presence of copper (II) ${ }^{\mathrm{b}}$, silver (I) ${ }^{\mathrm{b}}$, iron (III) ${ }^{\mathrm{b}}$ and cerium (IV) ${ }^{\mathrm{b}}$ in aqueous acetonitrile.

\begin{tabular}{llrrrr}
\hline & & \multicolumn{3}{c}{$\%$ of yield using } \\
\cline { 3 - 6 } Substrate & \multicolumn{1}{c}{ Products $^{c}$} & $\mathrm{Cu}^{2+}$ & $\mathrm{Ag}^{+}$ & $\mathrm{Fe}^{3+}$ & $\mathrm{Ce}^{4+}$ \\
\hline$p$-Ethylanisole & $p$-Methoxyacetophenone & 86 & 60 & 52 & 45 \\
$p$ - $n$-Propylanisole & $p$-Methoxypropiophenone & 85 & 58 & 50 & 45 \\
$p$-Methylanisole & $p$-Methoxybenzaldehyde & 65 & 48 & 45 & 42 \\
& $p$-Anisic acid & 18 & 10 & 8 & 8 \\
\hline
\end{tabular}

${ }^{a} \mathrm{Mol}$ ratio of peroxydisulphate was 2 ; ${ }^{\mathrm{b}} \mathrm{Mol}$ ratio of catalysts was $0 \cdot 2$, (i) $\mathrm{Cu}$ : copper sulphate; (ii) Fe: ferric ammonium sulphate; (iii) Ag: silver nitrate; (iv) Ce: cerric ammonium sulphate; ${ }^{c}$ Products were isolated either by distillation or by preparative TLC using 1:1 chloroform and hexane $\left(40-60^{\circ} \mathrm{C}\right)$, and identified by NMR and IR spectra.

We have also studied the oxidation of substituted naphthalenes with peroxydisulphate in presence of copper (II) in aqueous acetic acid. We obtained different types of products depending on the substrate and the results are summarised in table 3 . We observed low to moderate yields in this type of conversion. In all the cases we also recovered unreacted starting materials. Oxidation of naphthalene, 2-t-butylnaphthalene and 2,6-di- $t$-butylnaphthalene gives 1,4-naphthoquinone, 2- $t$-butyl-1,4-naphthoquinone and 2,6-di-t-butyl-1,4-naphthoquinone respectively, whereas 2-methyl and 1-methylnaphthalenes give 1,4-naphthoquinones, naphthalenemethyl acetates and naphthaldehydes. Oxidation of 1-phenyl or 1-bromonaphthalene gives a mixture of 2 or 5-substituted 1,4-naphthoquinones. Among them, 2-phenyl-1,4-naphthoquinone and 2-bromo-1,4-naphthoquinone involves a 1,2-shift (scheme 2). The formation of the 1,2-shift products constitutes additional evidence for the electron transfer mechanism (Periasamy and Bhatt 1977). Kinetic data show that the rate of oxidation of 
Table 3. Oxidation of substituted naphthalenes by peroxydisulphate $\mathrm{e}^{\mathrm{a}}-\operatorname{copper}(\mathrm{II})^{\mathrm{b}}$ in aqueous acetic acid.

\begin{tabular}{|c|c|c|c|c|}
\hline Substrate & Products $^{c}$ & $\begin{array}{l}\text { Yield } \\
(\%)\end{array}$ & $\begin{array}{l}\text { m.p. } \\
\left({ }^{\circ} \mathrm{C}\right)\end{array}$ & $\begin{array}{l}\text { Lit. m.p. } \\
\left({ }^{\circ} \mathrm{C}\right)\end{array}$ \\
\hline Naphthalene & 1,4-Naphthoquinone & 8 & 123 & $124-125^{1}$ \\
\hline $\begin{array}{l}\text { 2,6-Di-t-butyl- } \\
\text { naphthalene }\end{array}$ & $\begin{array}{l}\text { 2,6-Di-t-butyl-1,4- } \\
\text { naphthoquinone }\end{array}$ & 48 & $82-83$ & $83-84^{2}$ \\
\hline 2-t-Butylnaphthalene & $\begin{array}{l}\text { 2-t-Butyl-1,4-naphthoquinone } \\
\text { 6-t-Butyl-1,4-naphthoquinone }\end{array}$ & $\begin{array}{r}11 \\
2\end{array}$ & $\begin{array}{l}76 \\
57-58\end{array}$ & $\begin{array}{l}76-77^{3} \\
57-58^{4}\end{array}$ \\
\hline 2-Methylnaphthalene & $\begin{array}{l}\text { 2-Naphthaldehyde } \\
\text { 2-Naphthylmethyl acetate } \\
\text { 2-Methyl-1,4-naphthoquinone } \\
\text { 6-Methyl-1,4-naphthoquinone }\end{array}$ & $\begin{array}{l}3 \\
8 \cdot 5 \\
10 \\
1\end{array}$ & $\begin{array}{l}57 \\
59 \\
105-106 \\
90\end{array}$ & $\begin{array}{l}57-59^{5} \\
61^{6} \\
105-107^{7} \\
90-91^{8}\end{array}$ \\
\hline 1-Methylnaphthalene & $\begin{array}{l}\text { 1-Naphthaldehyde } \\
\text { 1-Naphthylmethyl acetate } \\
\text { 1,4-Naphthoquinone }\end{array}$ & $\begin{array}{l}3 \\
6 \\
4\end{array}$ & 123 & $124-125^{1}$ \\
\hline 1-Bromonaphthalene & $\begin{array}{l}\text { 2-Bromo-1,4-naphthoquinone } \\
\text { 5-Bromo-1,4-naphthoquinone }\end{array}$ & $\begin{array}{r}12 \\
6\end{array}$ & $\begin{array}{l}130 \\
159\end{array}$ & $\begin{array}{l}131^{9} \\
160-161^{10}\end{array}$ \\
\hline 1-Phenylnaphthalene & $\begin{array}{l}\text { 2-Phenyl-1,4-naphthoquinone } \\
\text { 5-phenyl-1,4-naphthoquinone }\end{array}$ & $\begin{array}{r}12 \cdot 6 \\
4 \cdot 5\end{array}$ & $\begin{array}{l}110 \\
166-167\end{array}$ & $\begin{array}{l}111-112^{11} \\
169-170^{12}\end{array}$ \\
\hline
\end{tabular}

${ }^{a} \mathrm{Mol}$ ratio of peroxydisulphate was 3 ; ${ }^{b} \mathrm{Mol}$ ratio of copper sulphate was 0.3 ; ${ }^{\text {P }}$ Products were isolated by preparative TLC using benzene as eluent and identified by NMR, IR and m.p. data. References ${ }^{1}$ Ho et al (1973); ${ }^{2}$ Contractor et al (1949); ${ }^{3}$ Bromby et al (1949); ${ }^{4}$ Periasamy and Bhatt (1978); ${ }^{5}$ Vogel (1959); ${ }^{6}$ Badger (1941); ${ }^{7}$ Smith and Webster (1937); ${ }^{8}$ Bendz (1951); ${ }^{9}$ McElvain and Engelhardt (1944); ${ }^{10}$ Fries and Kohler (1924); ${ }^{11}$ Padma and Hartman (1966); House et al (1972)<smiles>[R]c1cccc2ccccc12</smiles>

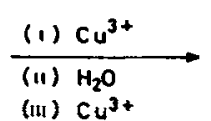

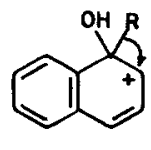<smiles>[R]c1ccc2ccccc2c1O</smiles><smiles>O=C1C=C(P)C(=O)c2ccccc21</smiles>

Scheme 2.

peroxydisulphate is different from the rate of oxidation of peroxydisulphate in presence of metal ions (House 1962). Oxidation of oxalate ion by peroxydisulphate in presence of copper and silver shows that the rate of reaction is ten times faster when using copper (II) catalyst as compared to silver (I) catalyst (Allen 1951). The above data also indicate that the copper ion is involved in the oxidation process.

\section{Experimental}

Melting points were determined on a Kofler hot stage apparatus and are uncorrected. The identity of the compounds was confirmed by comparison of IR and NMR spectra. 
IR spectra were recorded by the nujol mull technique on a Perkin-Elmer model 700 spectrometer and the NMR spectra were recorded in $\mathrm{CDCl}_{3}$ or $\mathrm{CCl}_{4}$ solution on a Varian T-60 spectrometer.

3.1 Preparative scale general procedure for the preparation of carbonyl compounds: Oxidation of p-ethylanisole

A solution of p-ethylanisole $(5.5 \mathrm{~g}, 0.04 \mathrm{~mol})$ in $140 \mathrm{ml}$ of acetonitrile was added to a solution of potassium peroxydisulphate $(21.6 \mathrm{~g}, 0.08 \mathrm{~mol})$ in $140 \mathrm{ml}$ of water and copper sulphate $(2 \mathrm{~g}, 0.008 \mathrm{~mol})$. The resulting mixture was stirred at $65-70^{\circ} \mathrm{C}$ for $3 \mathrm{~h}$. The reaction mixture was allowed to cool. The organic layer was separated and the solvent evaporated. The aqueous layer was extracted with ether and the extract washed with water, dried and concentrated. Both the residues were combined and distilled under reduced pressure to give $p$-methoxyacetophenone $(5.22 \mathrm{~g}, 86 \%)$; b.p. 120 $122^{\circ} \mathrm{C} / 10 \mathrm{~mm}$; m.p. $37-38^{\circ} \mathrm{C}$ (Lit b.p. $139^{\circ} \mathrm{C} / 15 \mathrm{~nm}$, Noller and Adams 1924).

\subsection{Oxidation of ethylbenzene: Typical general procedure}

A solution of ethylbenzene $(5.16 \mathrm{~g}, 0.049 \mathrm{~mol})$ in $180 \mathrm{ml}$ of acetic acid was added to a solution of potassium peroxydisulphate $(27.0 \mathrm{~g}, 0.1 \mathrm{~mol})$ in $120 \mathrm{ml}$ of water and copper sulphate $(2.5 \mathrm{~g}, 0.01 \mathrm{~mol})$. The resulting mixture was stirred at $80-85^{\circ} \mathrm{C}$ for $4 \mathrm{~h}$. The reaction mixture was allowed to cool, and then filtered, washed and extracted with methylene chloride. The methylene chloride extract was washed (4 times with water) and then dried, concentrated and distilled under reduced pressure. The first fraction gave acetophenone $(4.05 \mathrm{~g}, 70 \%)$; b.p. $78-80^{\circ} \mathrm{C} / 10 \mathrm{~mm}$; (Lit. b.p. $202-205^{\circ} \mathrm{C}$, Shriner and Turner 1930). The second fraction gave 1-phenyl-1-ethyl acetate $(1.06 \mathrm{~g}, 13.5 \%)$; b.p. $86-89^{\circ} \mathrm{C} / 10 \mathrm{~mm}$; (Lit. b.p. $105-108^{\circ} \mathrm{C} / 15 \mathrm{~mm}$, Marshall 1915).

\subsection{Oxidation of 2-methylnaphthalene: Typical small-scale procedure}

A solution of 2-methylnaphthalene $(465 \mathrm{mg}, 3.3 \mathrm{mmol})$ in $40 \mathrm{ml}$ of acetic acid was added to a solution of potassium peroxydisulphate $(2.64 \mathrm{~g}, 9.9 \mathrm{mmol})$ in $30 \mathrm{ml}$ of water and copper sulphate $(250 \mathrm{mg}, 10 \mathrm{mmol})$. The resulting mixture was stirred at $90-100^{\circ} \mathrm{C}$ for $5 \mathrm{~h}$. The reaction mixture was extracted with methylene chloride. The extract was washed with water and then dried and distilled. The crude products were separated by preparative TLC (silica gel/benzene). The product that moved faster (rendered visible by short exposure to iodine vapour) was isolated and identified as 2-naphthaldehyde $(16 \mathrm{mg}, 3 \%)$; m.p. $57^{\circ} \mathrm{C}$ (Lit. m.p. $59-60^{\circ} \mathrm{C}$, Vogel 1959). The second band was isolated and identified as 2-naphthalenemethyl acetate $(56 \mathrm{mg}, 8,5 \%)$; m.p. $59^{\circ} \mathrm{C}$ (Lit. m.p. $61^{\circ} \mathrm{C}$, Badger 1941). The third light-yellow coloured band was isolated and identified as 2-methyl-1,4-naphthoquinone (56 mg, 10\%); m.p. $104^{\circ} \mathrm{C}$ (Lit. m.p. 105-107 ${ }^{\circ} \mathrm{C}$, Smith and Webster 1937). The fourth yellow coloured band was isolated and identified as 6-methyl-1,4-naphthoquinone $(6 \mathrm{mg}, 1 \%)$; m.p. $90^{\circ} \mathrm{C}$ (Lit. m.p. $90-91^{\circ} \mathrm{C}$, Bendz 1951 ).

\section{References}

Allen T L 1951 J. Am. Chem. Soc. 733589

Asworth B, Gilbert B C, Homes R G G and Norman R O C 1978 J. Chem. Soc., Perkin II 951

Bacon R G R, Grime R and Munro D J 1954 J. Chem. Soc. 2275

Badger M 1941 J. Chem. Soc. 535

Baker W and Brown N C 1948 J. Chem. Soc. 2303 
Behrman E J 1963 J. Am. Chem. Soc. 853478

Bendz G 1951 Acta Chem. Scand. 5489

Bhatt M V and Perumal P T 1981 Tetrahedron Lett. 2605

Bromby N G, Peters A T and Rowe F M 1949 J. Chem. Soc. 144

Contractor R B, Peters A T and Rowe F M 1949 J. Chem. Soc. 1993

Elbs K 1893 J. Prakt. Chem. 48179

Fries K and Kohler K 1924 Chem. Ber. 57496

Giordano C and Belli A 1979 J. Org. Chem. 442314

Ho T L, Hall T W and Wong C M 1973 Synthesis 206

House D A 1962 Chem. Rev. 62185

House H O, Koepsell D G and Campbell J 1972 J. Org. Chem. 371003

Ledwith A and Russel P J 1974 J. Chem. Soc., Chem. Commun. 291

Marshall J 1915 J. Chem. Soc. 107523

McElvain S M and Engelhardt E L 1944 J. Am. Chem. Soc. 661077

Noller C R and Adams R $1924 \mathrm{~J}$. Am. Chem. Soc. 461893

Nyberg K and Wistrand L G 1978 J. Org. Chem. 432613

Ogata Y and Akada T 1970 Tetrahedron 26594

Padma A and Hartman R 1966 Tetrahedron Lett. 2277

Periasamy M and Bhatt M V 1977 Tetrahedron Lett. 2357

Periasamy M and Bhatt M V 1978 Synthesis 330

Perumal P T and Bhatt M V 1981 Indian J. Chem. B20 153

Perumal P T and Bhatt M V 1989 Proc. Indian Acad. Sci. (Chem. Sci.) 10125

Shriner R L and Turner T A 1930 J. Am. Chem. Soc. 521267

Smith L I and Webster I M 1937 J. Am. Chem. Soc. 59662

Vogel A I 1959 A text book of practical organic chemistry (London: Longman)

Walling C and Camaioni D M 1975 J. Am. Chem. Soc. 971603 